\title{
A Systematic Review of the Effectiveness of Group versus Individual Treatments for Adult Obesity
}

\author{
Virginia Paul-Ebhohimhen Alison Avenell \\ Health Services Research Unit, School of Medicine, University of Aberdeen, UK
}

\section{Key Words}

Obesity - Group versus individual .

Randomised controlled trials

\section{Summary}

Background: Both group and individual modes of delivery are employed for obesity treatments. Commercial weight loss groups commonly employ group-based delivery, while many clinical based settings employ one-to-one delivery. We systematically reviewed randomised controlled trials of treatments for adult obesity to compare the effectiveness of group-based to individual-based modes of treatment delivery. Methods: We searched 7 electronic databases and 2 journals and reviewed secondary references, based on a priori criteria to systematically review: randomised controlled trials of obesity treatments, participants with $\mathrm{BMI} \geq 28 \mathrm{~kg} / \mathrm{m}^{2}$, age $\geq 18$ years, comparison groups including at least 1 group-based and 1 individual-based treatment group, and follow-up $\geq 1$ year. We extracted data and conducted meta-analysis of weight change. Results: Eleven comparison groups from 5 qualifying trials were obtained, representing a total participant pool of 336. Significantly greater $(p=0.03)$ weight change at 12 months was found in group-based over individualbased treatment, and sub-analyses showed that increased effectiveness was associated with the use of financial reward and psychologist-led interventions. Conclusion: Group-based interventions were more effective than individual-based interventions among a predominantly female participant pool receiving psychologist-led interventions. Future studies to explore differences by professional group and interventions among men, which are accompanied by economic evaluation, are recommended.

\section{Introduction}

There is a need for effective and cost-effective approaches to obesity management that are well-tailored to the individual's needs. Exploring the effects of different modes and settings of delivery in treatments for obesity, such as the role of groupbased or individual-based treatments, is needed for evidencebased practice in the management of adult obesity, and to plan the design and evaluation of future interventions [1]. Groupbased interventions in obesity treatment offer the promise of being more resource-effective and the opportunity for enhanced social support, but are only rarely used in clinical settings, e.g. the UK National Health Service. They may, however, require more space for delivery and special skills in group leaders. In groups there may be more limited opportunities for attending to more specific individual needs, and all participants need to agree to set meeting times and location [2,3].

A previous analysis of group versus individually delivered obesity interventions conducted as part of a broader systematic review of randomised controlled trials (RCTs) [4] reported no significant differences in weight change at 12 months and 18 months but significant effects in favour of individual treatment at the 24-month follow-up. However, these analyses were conducted with few studies, and included some groups that differed in some aspects of treatments received (e.g. intensity, length or type of therapy) that could have influenced the results of comparisons. A second systematic review of group-based training for self-management strategies in people with type 2 diabetes reported clinically and statistically significant benefits (weight change was not among the main outcomes) for group-based patient-centred educational programmes [5], but also included some studies in which treatments received were not comparable across study arms and other studies that did not have any individual-based comparison treatment groups. Another review of group treatments for obese participants [6] also did not compare group to individual setting of delivery.

\begin{tabular}{ll}
\hline KARGER & $\oplus$ 2009 S. Karger GmbH, Freiburg \\
Fax +497614520714 & Accessible online at: \\
Information@Karger.de & www.karger.com/ofa \\
www.karger.com &
\end{tabular}

Dr. V. A. Paul-Ebhohimhen 
Table 1. Study selection criteria

\begin{tabular}{|c|c|}
\hline Study design & RCTs \\
\hline Participants & $\begin{array}{l}\text { Adults, aged } \geq 18 \text { years } \\
\text { Mean BMI } \geq 28 \mathrm{~kg} / \mathrm{m}^{2} \text { (except among ethnic groups with } \\
\text { obvious justification to allow for a lower cut-off BMI) } \\
\text { No groups with obesity-associated eating disorders, } \\
\text { e.g. binge eating disorder }\end{array}$ \\
\hline
\end{tabular}

Intervention

Any weight loss trial with at least one comparable groupbased intervention to individual-based intervention Follow-up for at least 1 year

Principal outcome Change in weight or BMI

This systematic review was therefore conducted to address the need for a focused systematic review of RCTs comparing groupbased versus individual-based setting for delivery of treatments for adult obesity to determine the long-term effectiveness (and cost-effectiveness if available) of each of these settings in treatments for adult obesity.

\section{Material and Methods}

This review was conducted following a pre-specified protocol and reported in keeping with the QUOROM statement [7].

Search Strategy

We searched through our existing database of RCTs and reviews of obesity treatments, made up of screened searches conducted in Medline, Embase, Cinahl, Psychinfo [4] and two update searches with citation alerts to July 2008 [8] for trials involving comparisons of group versus individual mode of delivery of treatments. We complemented this with hand searching for references in two obesity journals (Obesity Research (now Obesity) and the International Journal of Obesity) and cited in identified relevant articles.

Study Selection

Studies were retrieved independently by both reviewers and subjected to selection according to agreed a priori criteria as summarised in table 1.

\section{Quality Assessment}

Quality assessment was carried out by the first author on all retrieved relevant studies using the form originally designed in an earlier systematic review [4], and checked by the second author.

\section{Data Abstraction}

Using the same form from Avenell [4], data were abstracted by the first author and double-checked by the second author. Graphical data images were scanned onto a computer and analysed. Missing standard deviations (SD) were computed using the linear regression plot of the SD of the mean change in weight on the absolute mean change for weight derived in Avenell et al. [4].

\section{Data Analysis}

Meta-analysis, using Review Manager software RevMan version 4.2.10 (The Cochrane Collaboration, Oxford, UK), involving all possible comparison groups from our included studies, was first conducted, followed by pre-specified sub-analyses on whether or not rewards were used as

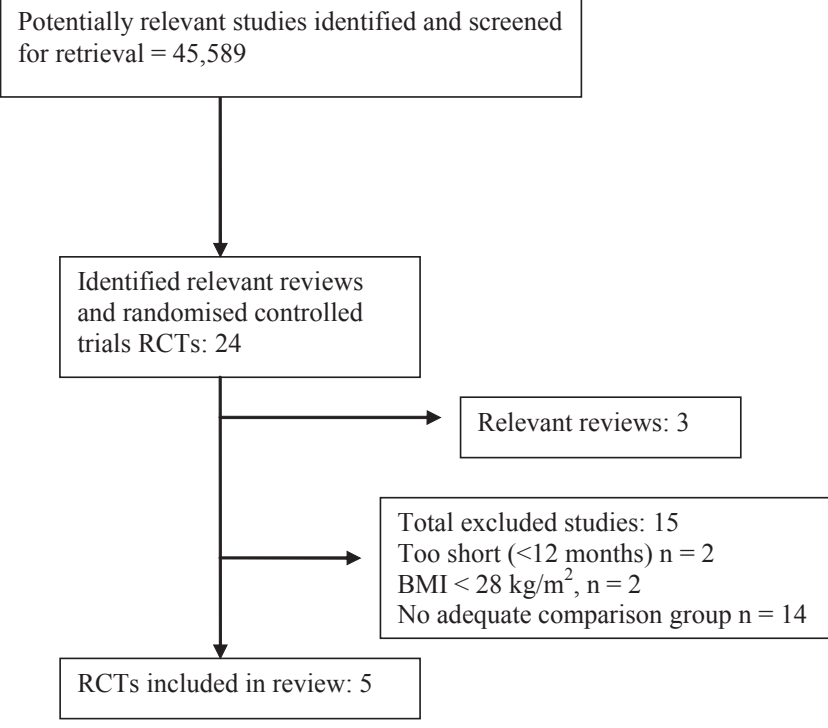

Fig. 1. Flow chart for selection of studies.

part of treatment and to compare interventions based on the health professional delivering the intervention.

Three planned sub-analyses (duration of intervention above and below the median time period, provision or non-provision of training in group therapy for providers of the intervention, and comparing multi-component to single component interventions) could not be conducted due to insufficient data. Heterogeneity across studies was explored and a fixed effects approach employed where $I^{2}$ was $<50 \%$ but a random effects approach employed where $I^{2}$ was $>50 \%$ [9].

\section{Results}

\section{Results of Search Strategy}

Details of the results of our search strategy are shown in figure 1.

\section{Quality of Included Studies}

No study gave details indicating concealment of random allocation. Blinding of participants was not mentioned in any included study, while outcome assessors' blinding was mentioned only in the most recent study by Waleekhachonloet [10]. Numbers of withdrawals were stated in all included studies and reasons for withdrawals given in two studies [11, 12]. Only one study [10] was analysed on an intention-to-treat basis.

\section{Description of Included Studies and Participants}

Details of the 5 included studies ( 1 in the UK, 3 in the USA, and 1 in Thailand) meeting the criteria for inclusion in this systematic review are shown in table 2.

One study included only men $[12,13]$ while in all other studies participants were women. Participants' ages ranged from 20 to 76 years, and BMI from 30 to $49 \mathrm{~kg} / \mathrm{m}^{2}$. Jeffery et al. [12, 13] gave details of the socioeconomic group with the mean social class being class III on a 5-point scale, and Waleekhachonloet et al. [10] gave the percentage of participants earning lower 


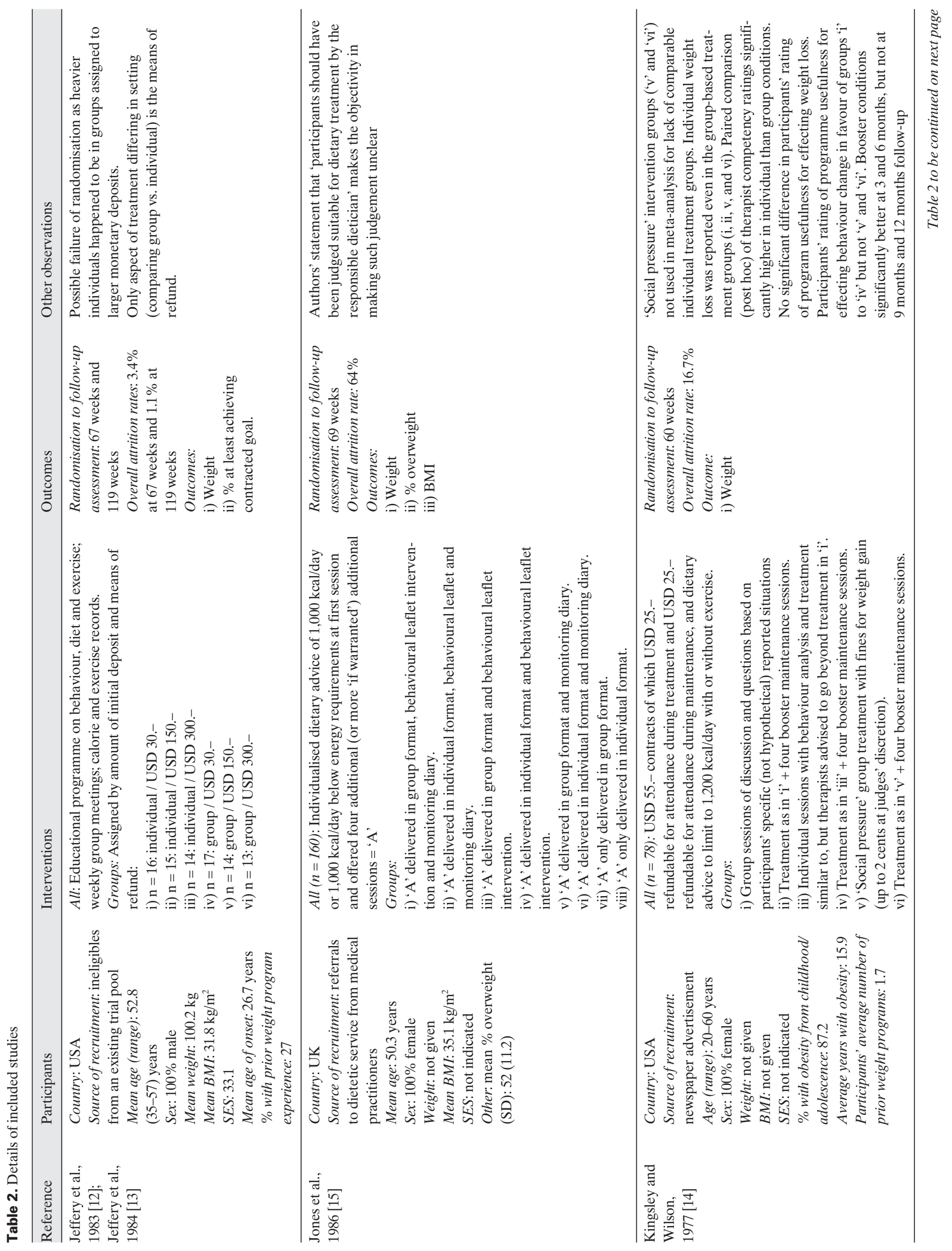




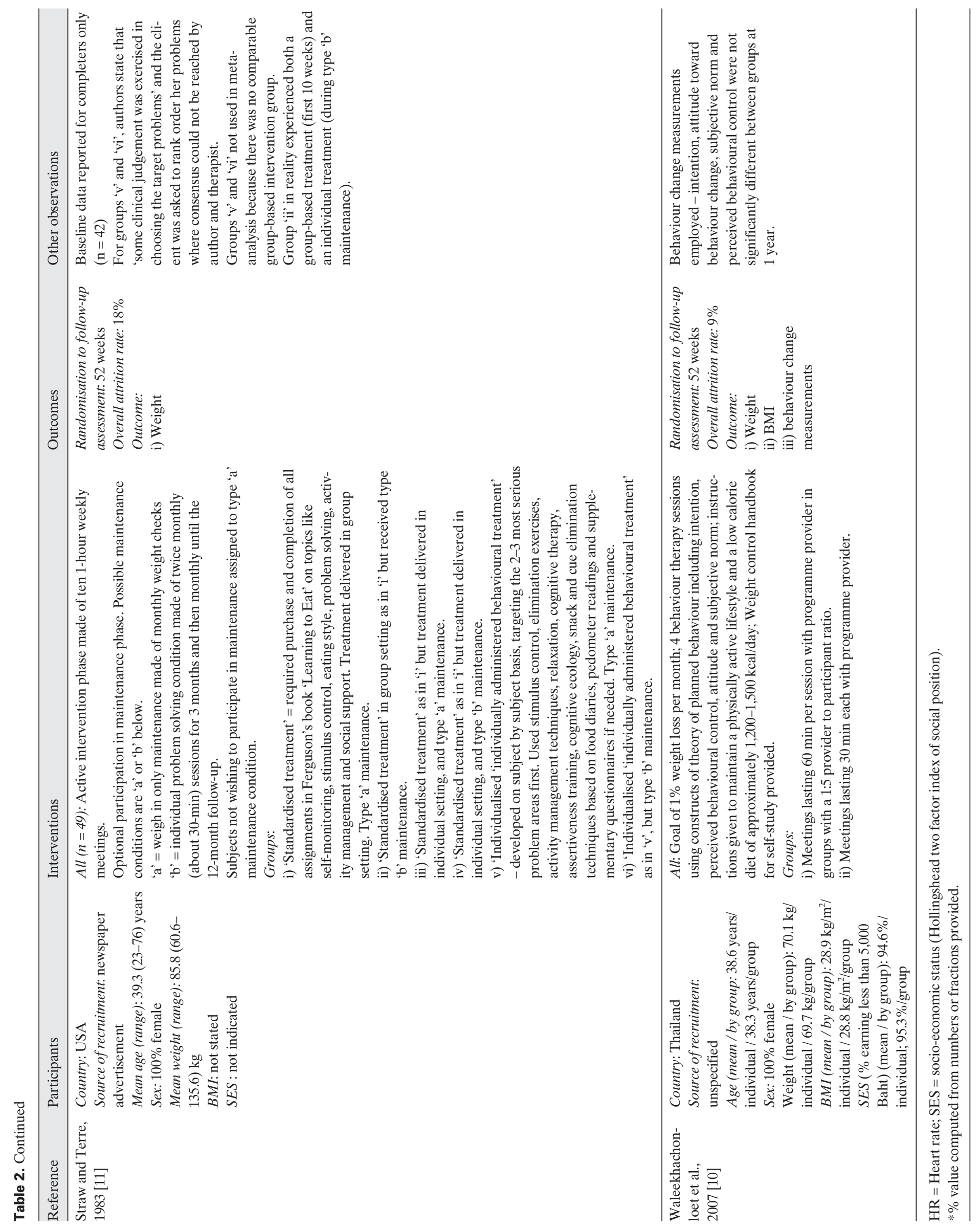


Table 3. Description of study groups used in meta-analyses

\begin{tabular}{|c|c|c|c|c|c|c|}
\hline $\begin{array}{l}\text { Study and year } \\
\text { (group vs. individual } \\
\text { comparison groups) }\end{array}$ & $\begin{array}{l}\text { Health } \\
\text { professional }\end{array}$ & $\begin{array}{l}\text { Active intervention/ } \\
\text { randomisation to } \\
\text { follow-up, weeks }\end{array}$ & $\begin{array}{l}\text { Group } \\
\text { therapy } \\
\text { training } \\
\text { provided }\end{array}$ & $\begin{array}{l}\text { Number } \\
\text { assigned to } \\
\text { 'group' } \\
\text { setting }\end{array}$ & $\begin{array}{l}\text { Monetary } \\
\text { reward } \\
\text { employed }\end{array}$ & $\begin{array}{l}\text { Multi-component } \\
\text { (details) }\end{array}$ \\
\hline $\begin{array}{l}\text { Jeffery et al., } 1983[12] \\
\text { (iv vs. i) }\end{array}$ & psychologist & $16 / 67$ & $\mathrm{U}$ & $\mathrm{U}$ & $\begin{array}{l}\text { Y (monetary } \\
\text { USD 30.- for } \\
\text { weight) }\end{array}$ & $\mathrm{Y}(\mathrm{B}$ and $\mathrm{L})$ \\
\hline $\begin{array}{l}\text { Jeffery et al., } 1983[12] \\
\text { (v vs. ii) }\end{array}$ & psychologist & $16 / 67$ & $\mathrm{U}$ & $\mathrm{U}$ & $\begin{array}{l}\text { Y (monetary } \\
\text { USD 150.- for } \\
\text { weight) }\end{array}$ & $\mathrm{Y}(\mathrm{B}$ and $\mathrm{L})$ \\
\hline $\begin{array}{l}\text { Jeffery et al. } 1983[12] \\
\text { (vi vs. iii) }\end{array}$ & psychologist & $16 / 67$ & $\mathrm{U}$ & $\mathrm{U}$ & $\begin{array}{l}\text { Y (monetary } \\
\text { USD 300.- for } \\
\text { weight) }\end{array}$ & $\mathrm{Y}(\mathrm{B}$ and $\mathrm{L})$ \\
\hline $\begin{array}{l}\text { Jones et al., } 1986[15] \\
\text { (i vs. ii) }\end{array}$ & dietician & $17 / 69$ & $\mathrm{~N}$ & $5-7$ & $\mathrm{~N}$ & $\begin{array}{l}\mathrm{Y}(\mathrm{B} \text { and } \mathrm{L} \text { with } \\
\text { monitoring diary })\end{array}$ \\
\hline $\begin{array}{l}\text { Jones et al., } 1986[15] \\
\quad \text { (iii vs. iv) }\end{array}$ & dietician & $17 / 69$ & $\mathrm{~N}$ & $5-7$ & $\mathrm{~N}$ & $\mathrm{Y}(\mathrm{B}$ and $\mathrm{L})$ \\
\hline $\begin{array}{l}\text { Jones et al., } 1986[15] \\
\text { (v vs. vi) }\end{array}$ & dietician & $17 / 69$ & $\mathrm{~N}$ & $5-7$ & $\mathrm{~N}$ & $\begin{array}{l}\mathrm{N} \text { (L with } \\
\text { monitoring diary) }\end{array}$ \\
\hline $\begin{array}{l}\text { Jones et al., } 1986[15] \\
\text { (vii vs. viii) }\end{array}$ & dietician & $17 / 69$ & $\mathrm{~N}$ & $5-7$ & $\mathrm{~N}$ & N (L only) \\
\hline $\begin{array}{l}\text { Kingsley and Wilson, } 1977 \text { [14] } \\
\text { (i vs. iii) }\end{array}$ & psychologist & $8 / 60$ & A & $\mathrm{U}$ & $\begin{array}{l}\text { Y (monetary } \\
\text { USD 50.- for } \\
\text { attendance) }\end{array}$ & Y (B and L) \\
\hline $\begin{array}{l}\text { Kingsley and Wilson, } 1977 \text { [14] } \\
\text { (ii vs. iv) }\end{array}$ & psychologist & $26 / 60$ & A & $\mathrm{U}$ & $\begin{array}{l}\text { Y (monetary } \\
\text { USD 50.- for } \\
\text { attendance) }\end{array}$ & $\mathrm{Y}(\mathrm{B}$ and $\mathrm{L})$ \\
\hline $\begin{array}{l}\text { Straw and Terre, } 1983[11] \\
\quad \text { (i vs. iii) }\end{array}$ & psychologist & $10 / 52$ & $\mathrm{~N}$ & $8-10$ & $\mathrm{~N}$ & $\mathrm{Y}(\mathrm{B}$ and $\mathrm{L})$ \\
\hline $\begin{array}{l}\text { Waleekhachonloet et al., } 2007 \text { [10] } \\
\text { (i vs. ii) }\end{array}$ & unspecified & $10 / 52$ & A & $3-12$ & $\mathrm{~N}$ & Y (B and L) \\
\hline
\end{tabular}

and higher than a monthly income of 5,000 Baht (USD 149.30). Ethnicity was not described in any of our included studies. Chronicity of obesity among participants was reported in two studies - in Kingsley and Wilson [14] the mean number of years with obesity was 15.9 and the percentage of participants with obesity since childhood or adolescence $82 \%$, and (our computed) difference between the reported mean age of participants and reported mean age of onset of obesity in Jeffery et al. [12, 13] was 26 years. Average number of previous formal weight loss attempts by participants was 1.7 in Kingsley and Wilson [14] while $27 \%$ of all participants reported previous formal attempts at weight loss in Jeffery et al. [12,13] which was a study undertaken in men only. No trial reported a pre-treatment programme prior to randomisation. Where mentioned, participants were excluded from the trial if they took medication known to affect weight $[10,14]$.

\section{Description of Interventions}

As shown in table 3, all groups used in meta-analyses received general lifestyle and nutrition advice. Stated numbers employed in the group-based treatment groups were between 5 and 7 in Jones et al. [15], 8 and 10 in Straw and Terre [11], and 3 and 12 in Waleekhachonloet et al. [10]. Provision of some training in the delivery of group-based interventions was only implied in two studies, namely Kingsley and Wilson [14] which stated a 'provision of a therapist orientation manual for all treatment conditions', and Waleekhachonloet et al. [10] which stated more generally that 'program providers were trained in nutrition, education and behavioural interventions'. No included studies were explicit about the provision of training in the delivery of group-based treatments.

Two studies employing the use of monetary reward. In the study of Jeffery et al. [12,13], assignment to intervention groups 


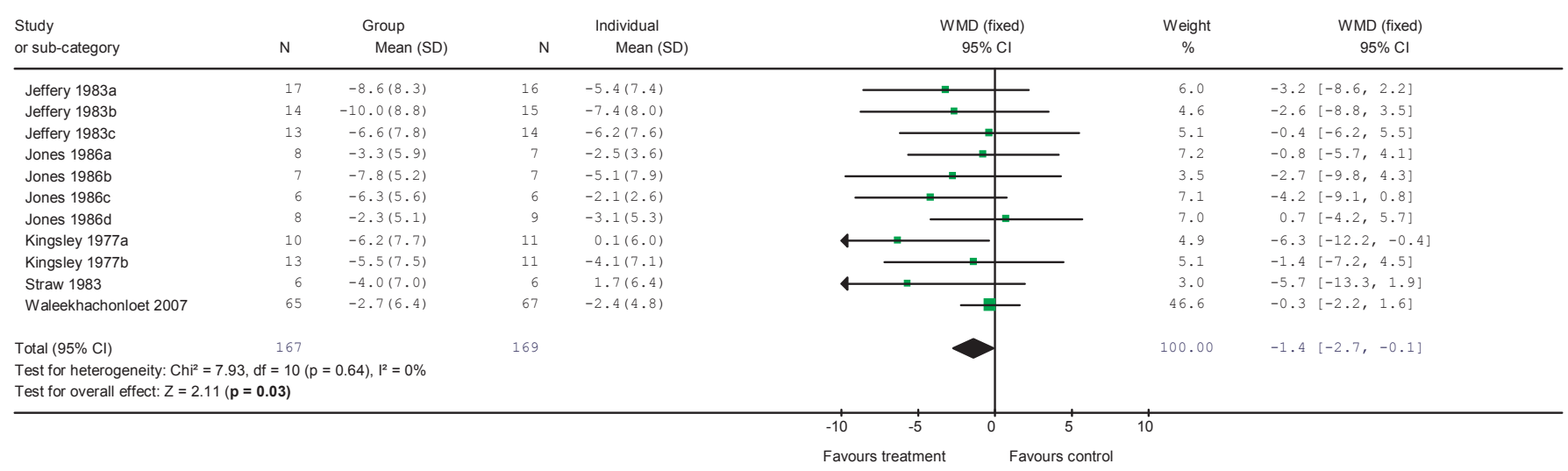

Fig. 2. Weight change $(\mathrm{kg})$ in group versus individual treatment at 12 months.

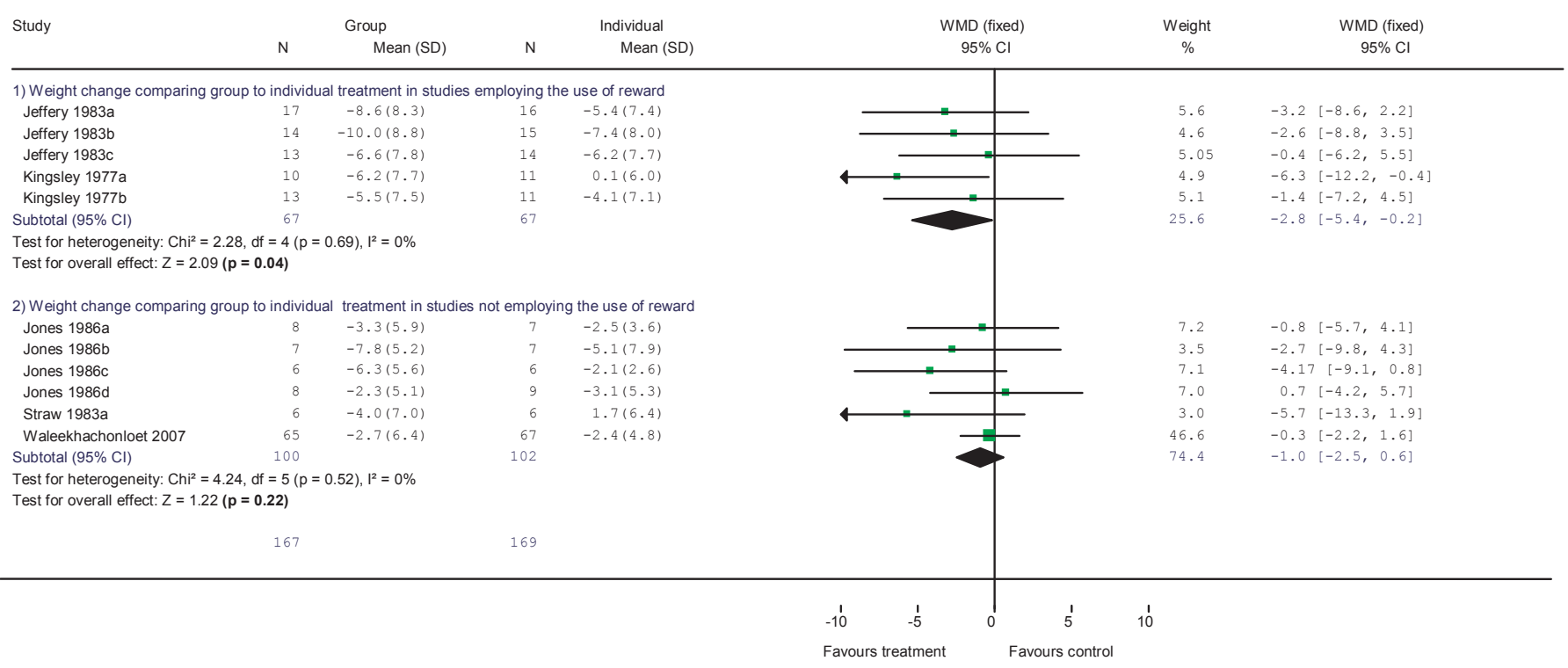

Fig. 3. Sub-analysis of comparison of group to individual treatment by use of financial reward.

was on the basis of varying the amount of monetary reward and the mode of delivery of this reward (reward for group performance or reward for individual performance); in the study of Kingsley and Wilson [14], all participants were required to make monetary deposits (refundable for attendance at treatment sessions).

\section{Results of Outcomes}

Attrition rates ranged from $3.4 \%$ in Jeffery et al. [12, 13], a study among respondents to an advertisement conducted by psychologists, with treatment involving the use of financial reward, to $64 \%$ in Jones et al. [15], a study conducted among referrals from health professionals by dieticians.

From the 11 comparable groups with group or individual treatment obtained from all five studies, we performed meta-analysis and sub-analyses on weight change at 1 year (fig. 2) and found a statistically significant weight change in group-based over in- dividual treatment with a weighted mean difference (WMD) of $-1.4 \mathrm{~kg}$ (95\% confidence interval ( $95 \% \mathrm{CI})-2.7$ to $-0.1 \mathrm{~kg})$.

Sub-analysis comparing group to individual treatment in trials employing the use of financial reward (fig. 3) gave a statistically significant effect in favour of group-based intervention with WMD for weight change at 1 year of $-2.8 \mathrm{~kg}$ (95\% CI -5.4 to $0.2 \mathrm{~kg}$ ), while comparing group to individual treatment in trials not involving the use of financial rewards showed no significant difference with a WMD for weight change at 1 year of $-1.0 \mathrm{~kg}$ (95\% CI -2.5 to $0.6 \mathrm{~kg}$ ).

Comparing group to individual treatment in the dieticianled comparison groups gave a non-significant difference with WMD for weight change at 1 year of $-1.6 \mathrm{~kg}$ (95\% CI -4.2 to $1.1 \mathrm{~kg}$ ), while comparing group to individual treatment in psychologist-led comparison groups gave a statistically significant difference with a WMD for weight change at 1 year of $-3.1 \mathrm{~kg}$ (95\% CI -5.5 to $-0.6 \mathrm{~kg}$ ). 


\section{Discussion}

In general, the studies did not report some important aspects of RCTs [16], such as the concealment of random allocation, blinding and intention-to-treat analysis. Numbers of dropouts were stated in all studies, and reasons were given in two studies $[11,12]$. The greatest attrition rates were recorded in dietician-led groups $(64 \%)$, compared to the rates recorded in the psychologist-led groups (range 3.4-18\%). Whether this difference is due to different kinds of individuals represented in the different study groups (the dietician-led groups were referred by health professionals while the psychologist-led groups were self-referred in response to adverts) or to differences in training and/or expertise between the dieticians and the psychologists remains to be explored.

Obesity prevalence is greatest in lower socio-economic groups, but only two studies described participants' socio-economic status $[10,12]$. Reporting of socio-economic status of participants would better inform the generalisability of findings. Details of the chronicity of obesity in participants and of previous weight loss attempts as given in two studies $[12,14]$ are also very useful in assessing the generalisability of findings.

Jones et al. [15] reported among inclusion criteria that participants were judged suitable for dietary treatment by the responsible dietician but gave no reference to any tools or guidelines used to ensure uniformity in judgement made by the dieticians. For reasons of external validity and generalisability, we suggest that future studies are more explicit about inclusion and exclusion criteria, protocols, guidelines or other validated tools employed. As noted earlier, we were only able to assume that some training in the delivery of group-based interventions was given to treatment providers in two trials $[10,14]$ and suggest that future studies or evaluated programmes are more explicit in reporting training in group therapy, and incorporate training and monitoring of the delivery of group-based interventions to treatment providers.

In evaluating the effectiveness of group-based interventions, it would be useful to have treatments that are validated and largely comparable across both group and individual comparison groups, and studies should include cost comparisons as was reported in Katz et al. [17].

Some excluded studies did not have comparable lifestyle interventions, intensity of intervention or ease of access to interventions. Such instances include Katz et al. [17] and Yeh et al. [18] who compared a novel group-based 'skill-building' intervention to an individual-based 'counselling' intervention; Ash et al. [19] who compared a group-based 'cognitive behaviour therapy' to individualised 'dietetic treatment'; Hakala [20] who compared a group counselling intervention (involving a 2-week in-patient period, up to 40 group sessions, a multidisciplinary team, and individual physician appointments) to an individual counselling group (receiving no in-patient treatment phase, and attending 15 maximum possible physician visits); Long et al. [21] who compared individual treatment groups attending 'weekly weigh-ins with opportunity for feedback' to a group treatment with participants attending ' 4 brief weigh-ins' only; and Perri et al. [22] who compared individual treatment participants required to perform home-based exercise to group-based treatment participants who had to access the exercise facility away from home.

Meta-analysis of our included studies showed that groupbased interventions are significantly more effective than individual-based interventions. One study excluded for lasting only 6 months [3], in which participants' preferences were assessed before randomisation to individual- or group-based treatment, also reported group-based treatments to be significantly more effective than individual-based treatments even among participants with expressed preference for the individual setting.

We conclude that group-based interventions are more effective than individual-based interventions in the population represented by the participants in our included studies. Groupbased interventions are also potentially more resource-saving in terms of total health professional hours involved per participant. Future cost-effectiveness modelling or economic evaluation studies that incorporate other resources such as the costs for space or for social contacts (e.g. phone call reminders among 'group-based' participants) and other perspectives (e.g. societal) could help in informing the development of evidence-based guidelines. We therefore recommend that any future trials or evaluation of group and individual treatments for obesity are accompanied by an economic evaluation. Sensitivity analyses incorporating the costs and effects due to co-morbidities attributable to obesity could further inform the evidence base for decision-makers to provide infrastructure in favour of group-based rather than individualbased services for obesity management. We also found that incorporating financial rewards in treatment is associated with greater effectiveness of obesity treatments. Only one trial [12, 13] was conducted in men, so more work is needed to examine the use of group-based approaches in men. Findings from the sub-analyses of groups represented in this systematic review may suggest that psychologists are more effective at group therapy than dieticians (although only one trial had dietician-led groups and recruitment of participants differed). We therefore recommend studies to explore reasons for observed differences in outcome between dieticians and psychologists which might inform training needs.

One of our excluded studies (recruited as groups or as individuals, but did not compare group to individual treatment) [23] has been cited in support of greater success being reported in interventions providing peer support than in interventions without peer support [24]. Although our systematic review was not aimed at comparing the provision of structural support (and there was no report in any of our included studies that the groups in the group-based treatment groups were formed from available significant others) or the provision of 
functional support (subjective measure of perception of support by the recipient of the intervention), it is assumed that participants in the group-based treatment groups could have developed peer relationships leading to the modification of the social network of participants. Findings in this review are thus in principle in keeping with the statement by Christakis and Fowler [24] that weight loss interventions that provide peer support (thus modifying the social network) are more successful than those that do not.

\section{Acknowledgements}

The Health Services Research Unit is funded by the Chief Scientist Office of the Scottish Government Health Directorates. Alison Avenell is funded by a Career Scientist Award from the Chief Scientist Office of the Scottish Government Health Directorates.

\section{Disclosure}

The authors declared no conflict of interest.

\section{References}

$>_{1}$ Campbell M, Fitzpatrick R, Haines A, Kinmonth AL, Sandercock P, Spiegelhalter D, Tyrer P: Framework for design and evaluation of complex interven tions to improve health. BMJ 2000;321:694-696.

$\checkmark 2$ Ayala GX: An experimental evaluation of a groupversus computer-based intervention to improve food portion size estimation skills. Health Educ Res 2006; 21:133-145.

-3 Renjilian DA, Perri MG, Nezu AM, McKelvey WF, Shermer RL, Anton SD: Individual versus group therapy for obesity: effects of matching participants to their treatment preferences. J Consult Clin Psychol 2001;69:717-721.

4 Avenell A, Broom J, Brown TJ, Poobalan A, Aucott L, Stearns SC, Smith WC, Jung RT, Campbell MK, Grant AM: Systematic review of the long-term effects and economic consequences of treatments for obesity and implications for health improvement. Health Technol Assess 2004;8:21.

5 Deakin T, McShane CE, Cade JE, Williams RDRR: Group based training for self-management strategies in people with type 2 diabetes mellitus. Cochrane Database Syst Rev 2005;2:CD003417. www.cochrane.org/reviews/en/ab003417.html.

6 Melcarne R, Cognolato S, Santonastaso P: Group therapy programmes for obese patients. Minerva Gastroenterol Dietol 1996;42:27-38.

7 Moher D, Cook DJ, Eastwood S, Olkin I, Rennie D, Stroup DF: Improving the quality of reports of meta-analyses of randomised controlled trials: the QUOROM statement. Lancet 1999;354:1896-1900.

$\checkmark 8$ Paul-Ebhohimhen V, Avenell A: Long-term effects of financial incentives on treatments for obesity: a systematic review of randomised controlled trials. Obes Rev 2007;9:355-367.
9 Higgins JPT, Thompson SG, Deeks JJ, Altman DG: Measuring inconsistency in meta-analyses. BMJ 2003; 327:557-560.

10 Waleekhachonloet O, Limwattananon C, Limwattananon S, Gross CR: Group behavior therapy versus individual behavior therapy for healthy dieting and weight control management in overweight and obese women living in rural community. Obes Res Clin Pract 2007;12:223-232.

11 Straw MK, Terre L: An evaluation of individualized behavioral obesity treatment and maintenance strategies. Behav Ther 1983;14:255-266.

12 Jeffery RW, Gerber WM, Rosenthal BS, Lindquist RA: Monetary contracts in weight control: effectiveness of group and individual contracts of varying size. J Consult Clin Psychol 1983;51:242-248.

13 Jeffery RW, Bjornson-Benson WM, Rosenthal BS, Lindquist RA, Johnson SL: Behavioral treatment of obesity with monetary contracting: two-year followup. Addict Behav 1984;9:311-313.

14 Kingsley RG, Wilson GT: Behavior therapy for obesity: a comparative investigation of long-term efficacy. J Consult Clin Psychol 1977;45:288-298.

15 Jones SE, Owens HM, Bennett GA: Does behaviour therapy work for dietitians? An experimental evaluation of the effects of three procedures in a weight reduction clinic. Hum Nutr Appl Nutr 1986;40: 272-281.

16 Moher D, Schulz KF, Altman DG: The CONSORT statement: revised recommendations for improving the quality of reports of parallel group randomized trials. Lancet 2001;357:1191-1194.

17 Katz DL, Chan W, Gonzalez M, Larson D, Nawaz H, Abdulrahman M, Yeh MC: Technical skills for weight loss: preliminary data from a randomized trial. Prev Med 2002;34:608-615.
18 Yeh MC, Rodriguez E, Nawaz H, Gonzalez M, Nakamoto D, Katz DL: Technical skills for weight loss: 2-y follow-up results of a randomized trial. Int J Obes Relat Metab Disord 2003;27:1500-1506.

19 Ash S, Reeves M, Bauer J, Dover T, Vivanti A, Leong C, Sullivan TO, Capra S: A randomised control trial comparing lifestyle groups, individual counselling and written information in the management of weight and health outcomes over 12 months. Int J Obes 2006;30:1557-1564.

20 Hakala P, Karvetti RL, Ronnemaa T: Group vs. individual weight reduction programmes in the treatment of severe obesity - a five year follow-up study. Int J Obes Relat Metab Disord 1993;17:97-102.

21 Long CG, Simpson CM, Allott EA: Psychological and dietetic counselling combined in the treatment of obesity: a comparative study in a hospital outpatient clinic. Hum Nutr Appl Nutr 1983;37:94-102.

22 Perri MG, Martin AD, Leermakers EA, Sears SF, Notelovitz M: Effects of group- versus home-based exercise in the treatment of obesity. J Consult Clin Psychol 1997;65:278-285.

23 Wing RR, Jeffery RW: Benefits of recruiting participants with friends and increasing social support for weight loss and maintenance. J Consult Clin Psychol 1999;67:132-138

24 Christakis NA, Fowler JH: The spread of obesity in a large social network over 32 years. N Engl J Med 2007;357:370. 